\title{
The High Temperature Reaction of Carbon with Nitric Oxide
}

\author{
J.-M. COMMANDRÉ, B. R. STANMORE*, and S. SALVADOR \\ Laboratoire de Génie des Procédés des Solides Divisés, UMR 2392 CNRS, Ecole des Mines d'Albi-Carmaux, \\ Campus Jarlard, Route de Teillet, 81000 Albi, France
}

\begin{abstract}
Four pyrolyzed carbonaceous materials were reacted with $950 \mathrm{ppm}$ of nitric oxide (in $\mathrm{N}_{2}$ ) in an entrained flow furnace at temperatures between 800 and $1,000^{\circ} \mathrm{C}$. Their apparent reactivities, corrected for mass transfer, when calculated on a BET area basis displayed a wide spread of values. However, when recalculated for the surface area estimated for pores greater than $20 \mathrm{~nm}$ in size, as measured by mercury porosimetry, far better agreement was obtained. The results are consistent with other data in the literature, for which equivalent surface areas were available.
\end{abstract}

\section{INTRODUCTION}

Knowledge of the kinetics of the reaction $\mathrm{NO}+$ $\mathrm{C}_{\mathrm{s}} \rightarrow \mathrm{CO}+1 / 2 \mathrm{~N}_{2}$ is essential for the prediction of fuel-NO formed by burning solid fuels. Unfortunately, the experimental results reported in the literature for similar conditions can extend over three orders of magnitude [1]. It is also found that there is a characteristic 'break' in the Arrhenius plot for this reaction, with the activation energy increasing above that point. The break temperatures found in the literature range from 850 to $1,075 \mathrm{~K}$. Visona and Stanmore [2] have pointed to the significant differences in model output obtained with different kinetic expressions. For coal chars at temperatures above the break, they found that it was necessary to use a high rate expression from Chan et al. [3] to obtain a realistic extent of reaction. The rationale behind this choice was pure pragmatism, and the physicochemical principles behind the reaction remain uncertain.

For a collection of experimental data, Aarna and Suuberg [1] found that plots on an area basis (measured by BET) lead to a closer grouping of results than on a mass basis. Graphites and non-coal chars are generally less reactive than coal chars. Even so, considerable divergence is apparent. They identify the catalytic effect of minerals and the promotion of the reaction by carbon monoxide as two confounding influences. For a range of coal chars they produced a mean correlation for the overall reaction rate constant of the form

\footnotetext{
*Corresponding author. E-mail: stanmore@enstimac.fr
}

$$
\begin{aligned}
& \mathrm{k}_{\mathrm{NO}}= 5.5 \times 10^{6} \exp (-15939 / \mathrm{T}) \\
& \mathrm{g}_{\mathrm{NO}} \mathrm{m}^{-2} \mathrm{~h}^{-1} \mathrm{~atm}_{\mathrm{NO}}^{-1}
\end{aligned}
$$

This expression implies that the reaction is first order with respect to NO, which is usually found to be the case, although with significant exceptions. In view of the number of data sets involved, the activation energy of $133 \mathrm{~kJ} \mathrm{~mol}^{-1}$ should be reliable, but the pre-exponential factor represents the mean of a wide range.

\section{EXPERIMENTAL, RESULTS, AND DISCUSSION}

In view of this uncertainty, the prediction of NO destruction is best done with measured kinetics. Therefore, we measured experimentally the reaction kinetics of four chars prepared from carbonaceous materials used industrially. The entrained flow reactor used is described elsewhere [4]. The solid was fed at $1.5 \mathrm{~g} \mathrm{~min}^{-1}$ in $10 \mathrm{Nl} \mathrm{min} \mathrm{m}^{-1}$ of a mixture of $955 \mathrm{ppm}$ of $\mathrm{NO}$ in nitrogen. The uniform hot zone was $80 \mathrm{~mm}$ in diameter and $0.9 \mathrm{~m}$ in length which provided a gas residence time of $\sim 4 \mathrm{~s}$. The temperatures used in the experiments of this study were 800,900 , and $1,000^{\circ} \mathrm{C}$, which are all above the highest reported 'break' temperature for the $\mathrm{C}-\mathrm{NO}$ reaction in the literature. At least two separate determinations at each temperature were made for each solid.

The solids were two petroleum cokes, Bonna and CDP (coke de petrole), a commercial activated carbon and a coal, which was a bituminous product from the Ivan mine. Each material was screened to a size fraction of $-100+30$ $\mu \mathrm{m}$, and pyrolyzed to char by passing it with $3 \%$ 
TABLE 1

Properties of Chars $\left(900^{\circ} \mathrm{C}\right)$

\begin{tabular}{lcccc}
\hline Property & Petroleum coke Bonna & Petroleum coke CDP & Activated carbon & Ivan Coal \\
\hline Prox. analysis $(\mathrm{db})$ & & & & \\
$\quad$ Volatile matter & 8.7 & 8.6 & 17.7 & 16.6 \\
$\quad$ Ash & 1.3 & 0.7 & 2.7 & 18.4 \\
Ultimate analysis (daf) & & & & \\
$\mathrm{C}$ & 87.1 & 84.0 & 85.9 & 71.0 \\
$\mathrm{H}$ & 1.4 & 1.3 & 0.6 & 1.1 \\
$\mathrm{~N}$ & 1.8 & 1.3 & 0.5 & 2.1 \\
$\mathrm{~S}$ & 4.34 & 6.96 & 0.11 & 0.32 \\
Surface Area $\left(\mathrm{m}^{2} \mathrm{~g}^{-1}\right)$ & & & & \\
$\mathrm{BET}$ & 7.2 & 10.0 & 890 & 64 \\
$\mathrm{Hg}$ & 8.8 & 2.2 & 0.7 & 8.3 \\
Porosity & 0.730 & 1640 & 1810 & 1670 \\
True density $\left(\mathrm{kg} \mathrm{m}^{-3}\right)$ & 1710 & 770 & 488 & 106 \\
Exit NO conc. @ $900^{\circ} \mathrm{C}(\mathrm{ppm})$ & 608 & & & \\
\hline
\end{tabular}

$\mathrm{O}_{2}$ in nitrogen through the furnace at $900^{\circ} \mathrm{C}$ under the feed conditions specified above. Only the coal char contained a significant quantity of ash. Both nitrogen adsorption (BET) and mercury penetration tests were carried out. The true densities and hence porosities were measured by helium pycnometry. The analyses of the pyrolyzed carbons are listed in Table 1 and the cumulative surface areas (against pore size) as found by porosimetry are presented in Fig. 1.

Concentrations of NO were measured with a

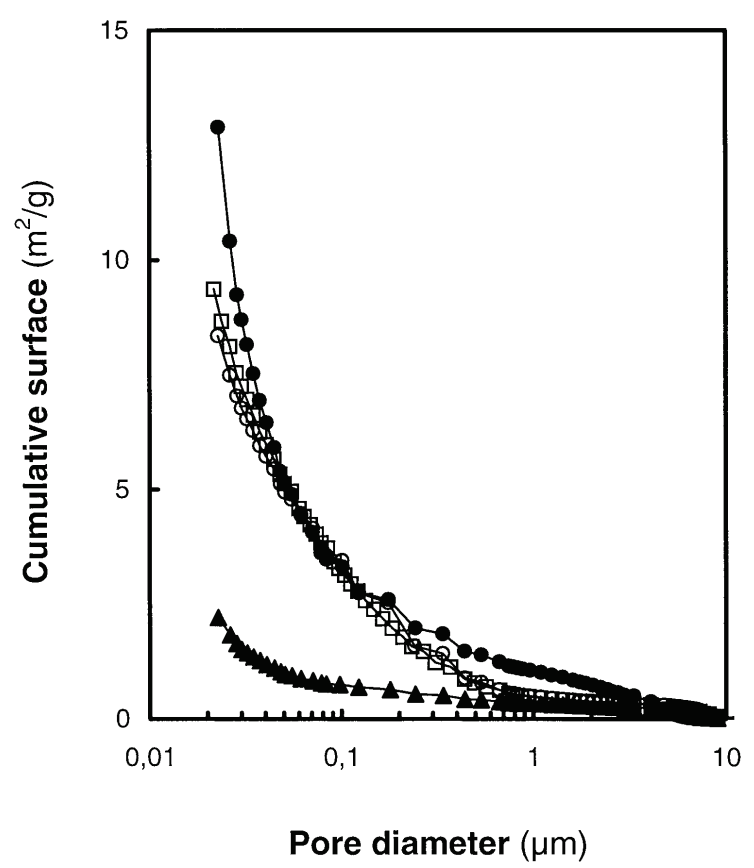

Fig. 1. Cumulative pore area as a function of pore size, measured by mercury intrusion: $\square$ Bonna petcoke, $\boldsymbol{\Delta}$ CDP petcoke, activated carbon, o Ivan char.
Servomex online NDIR analyser from a sample representing $80 \%$ of the total flow. Careful tests reported previously [4] have shown that radial mixing is good in this reactor at the flowrates used. The maximum fluctuations in NO output were $\pm 15 \mathrm{ppm}$. A mean exit value for [NO] integrated over the time of the test was obtained from the electronic output. The values found at $900^{\circ} \mathrm{C}$ are included in Table 1 . Less than $0.1 \%$ of the carbon was removed from the solid samples. The system was sometimes run without solid to ensure that no other reaction of NO was occurring. The outlet value was always within $15 \mathrm{ppm}$ of the inlet.

The rate of production of $\mathrm{NO} \mathrm{r}_{\mathrm{NO}}\left(\mathrm{mol}_{\mathrm{NO}}\right.$ $\mathrm{kg}^{-1} \mathrm{~s}^{-1} \mathrm{~Pa}^{-1}$ ) was derived from the exit NO concentrations as follows. From an NO balance the rate of removal of $\mathrm{NO}$ at a distance $\mathrm{z}$ down the furnace tube is

$\frac{\mathrm{dy}}{\mathrm{dz}}=-\frac{\mathrm{r}_{\mathrm{NO}} \mathrm{PP} \phi \mathrm{A}}{\mathrm{V}} \mathrm{m}^{-1}$

where $\mathrm{y}$ is the mole fraction of $\mathrm{NO}, \mathrm{P}$ is the total pressure $(\mathrm{Pa}), \phi$ is the solids loading $\left(\mathrm{kg} \mathrm{m}^{-3}\right), \mathrm{A}$ is the cross-sectional area of the tube $\left(\mathrm{m}^{2}\right)$ and $\mathrm{V}$ is the molar flowrate of gas $\left(\mathrm{mol} \mathrm{s}^{-1}\right)$. Because the temperature and the solids loading are constant and the consumption of NO is negligible in terms of the total flow, Eq. 2 can be integrated to give

$\mathrm{r}_{\mathrm{NO}}=-\frac{\mathrm{V}}{\mathrm{P} \phi \mathrm{AZ}} \ln \frac{\mathrm{y}_{\text {out }}}{\mathrm{y}_{\mathrm{in}}} \mathrm{mol}_{\mathrm{NO}} \mathrm{kg}^{-1} \mathrm{~s}^{-1} \mathrm{~Pa}_{\mathrm{NO}}^{-1}$ 
where $\mathrm{Z}$ is the total length of the hot zone $(\mathrm{m})$. Although there would be some particle slip through the gas, the gas residence time remains unaffected. The effective solids loading was calculated from the ratio: (solids residence time)/(gas residence time) to allow for the shorter residence time resulting from the slip (terminal) velocity of the solids. The value of $\mathrm{r}_{\mathrm{NO}}$ is an apparent rate, which does not take account of internal or external mass transfer limitations.

The mass transfer limitations concerning the particles must be evaluated, both externally and internally. For external mass transport, it has been found that radial mixing is adequate [4] and molecular diffusion rates will maintain the surface concentration of NO at the bulk level. Within the particles, their small size (30-100 $\mu \mathrm{m})$ and high porosity, and the comparatively low temperatures will favor complete penetration by NO. The effective diffusion coefficients for calculating effectiveness factors were estimated by means of the standard pore model proposed by Satterfield [5], using pore diameters calculated from the porosity $\epsilon$, the particle density $\rho_{\mathrm{p}}$ and the pore surface area $\mathrm{S}\left(\mathrm{m}^{2} \mathrm{~kg}^{-1}\right)$

$\mathrm{d}_{\text {pore }}=\frac{4 \varepsilon}{\rho_{\mathrm{p}} \mathrm{S}}$

The Knudsen diffusion coefficient is then

$\mathrm{D}_{\mathrm{knu}}=\frac{\mathrm{d}_{\text {pore }}}{3}\left(\frac{8 \mathrm{RT}}{\pi \mathrm{M}_{\mathrm{NO}}}\right)^{0.5}$

where $\mathrm{M}_{\mathrm{NO}}$ is the molecular mass of NO. The effective diffusivity is assumed to be

$\mathrm{D}_{\mathrm{ef}}=\frac{\varepsilon}{\tau}\left(\frac{1}{\mathrm{D}_{\mathrm{m}}}+\frac{1}{\mathrm{D}_{\mathrm{knu}}}\right)^{-1}$

where $\tau$ is the tortuosity and $\mathrm{D}_{\mathrm{m}}$ the molecular diffusion coefficient. Then the Thiele modulus and effectiveness factor are given by

$\phi=\frac{\mathrm{d}_{\mathrm{p}}}{2}\left(\frac{\mathrm{k}_{\mathrm{NO}} \beta \mathrm{SP}_{\mathrm{NO}}}{\mathrm{M}_{\mathrm{NO}} \mathrm{D}_{\mathrm{ef}}[\mathrm{NO}]}\right)^{0.5}$

$\eta=\frac{3}{\phi}\left(\frac{1}{\tanh \phi}-\frac{1}{\phi}\right)$

where $\beta$ is the stoichiometric co-efficient for the reaction between $\mathrm{NO}$ and carbon, $\mathrm{P}_{\mathrm{NO}}$ is the
TABLE 2

Effectiveness Factors Calculated for the C-NO Reaction using BET and $\mathrm{Hg}_{20}$ Area Bases

\begin{tabular}{|c|c|c|c|c|c|c|}
\hline & \multicolumn{2}{|c|}{$800^{\circ} \mathrm{C}$} & \multicolumn{2}{|c|}{$900^{\circ} \mathrm{C}$} & \multicolumn{2}{|c|}{$1000^{\circ} \mathrm{C}$} \\
\hline & BET & $\mathrm{Hg}_{20}$ & BET & $\mathrm{Hg}_{20}$ & BET & $\mathrm{Hg}_{2 \mathrm{O}}$ \\
\hline Bonna coke & $\sim 1$ & $\sim 1$ & 0.99 & 0.97 & 0.96 & 0.96 \\
\hline CDP coke & $\sim 1$ & $\sim 1$ & 0.97 & 0.99 & 0.84 & 0.94 \\
\hline Activated carbon & 0.97 & $\sim 1$ & 0.90 & $\sim 1$ & 0.79 & 0.99 \\
\hline Ivan char & 0.90 & 0.97 & 0.81 & 0.93 & 0.70 & 0.88 \\
\hline
\end{tabular}

partial pressure of $\mathrm{NO}(\mathrm{Pa})$ and $[\mathrm{NO}]$ is its molar concentration. The values of effective diffusion co-efficient found at $800^{\circ} \mathrm{C}$ for the Ivan char were $5.6 \times 10^{-6} \mathrm{~m}^{2} \mathrm{~s}^{-1}$ (BET area) and $16.8 \times 10^{-6} \mathrm{~m}^{2} \mathrm{~s}^{-1}\left(\mathrm{Hg}_{20}\right)$, compared to a value of $6.9 \times 10^{-6} \mathrm{~m}^{2} \mathrm{~s}^{-1}$ measured experimentally by Johnsson and Jensen [6] in a bituminous coal char. The values of the effectiveness factors are given in Table 2. Because the results are mostly close to unity, they are comparatively insensitive to the values of the effective diffusion co-efficients.

The true (intrinsic) rate coefficient in area terms, $\mathrm{k}_{\mathrm{NO}}$, was found from the rate, $\mathrm{r}_{\mathrm{NO}}$ by

$\mathrm{k}_{\mathrm{NO}}=\frac{\mathrm{r}_{\mathrm{NO}}}{\eta \mathrm{S}} \quad \mathrm{mol}_{\mathrm{NO}} \mathrm{m}^{-2} \mathrm{~s}^{-1} \mathrm{~Pa}_{\mathrm{NO}}^{-1}$

where $\eta$ is the effectiveness factor. The value of $\mathrm{k}_{\mathrm{NO}}$ must be corrected for effectiveness to calculate the Thiele modulus, and hence to restimate $\eta$. This was carried out iteratively by fitting an activation energy to the three results, calculating pre-exponential factors and recalculating the effectiveness factors. The reactivity results are depicted as individual points on Fig. 2 (units $\mathrm{mol}_{\mathrm{NO}} \mathrm{m}^{-2} \mathrm{~s}^{-1} \mathrm{~atm}_{\mathrm{NO}}{ }^{-1}$ ) using the BET areas. One petroleum coke (Bonna) is $\sim 50 \%$ more reactive than the other (CDP), but both results lie well above the line of Eq. 1. Their activation energies are close to that of Eq. 1, viz. $133 \mathrm{~kJ}$ $\mathrm{mol}^{-1}$. The results for the activated carbon fall near Eq. 1, again with the same activation energy. The Ivan char is much more reactive than the other carbons.

The wide scatter found here reflects the outcomes of two recent reviews [1, 7]. This is further illustrated in Fig. 2 by some recent data that were not included in those reviews. The reactivities of one coal char [6] falls on Eq. 1, 


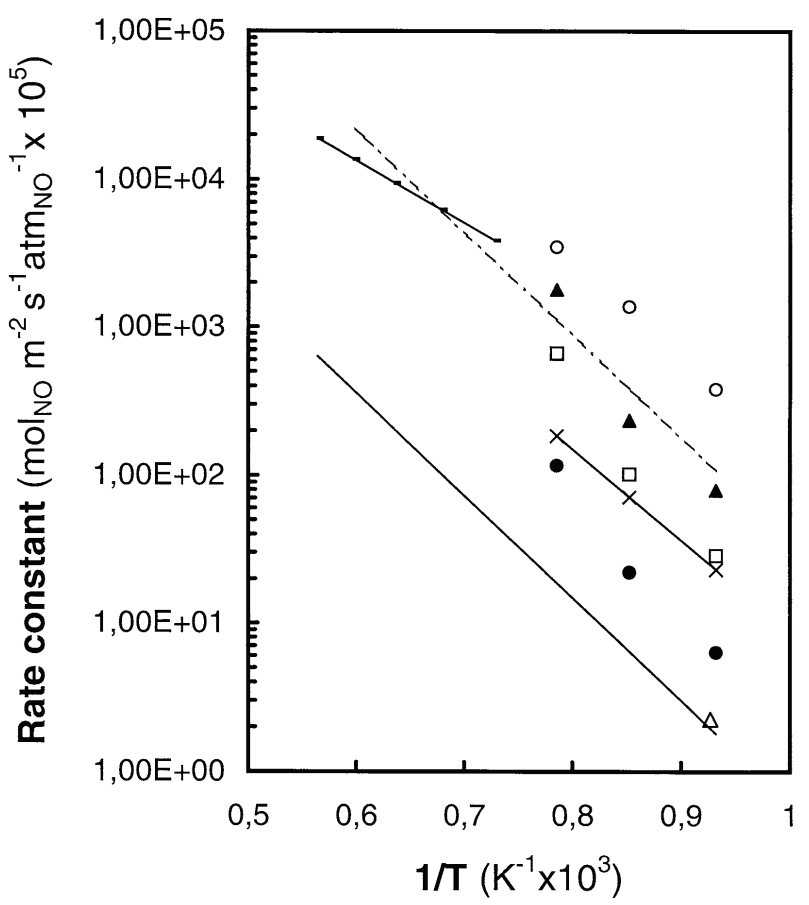

Fig. 2. Dependence of the $\mathrm{C}-\mathrm{NO}$ reaction rate on temperature, specified on BET areas $\square$ Bonna petcoke, $\Delta$ CDP petcoke, activated carbon, $\bigcirc$ Ivan char, Eq. $1,-\cdot-\cdot-$ Eq. 10, , , , carbon black [13], $-\times-$ coal char [10], $\Delta$ coal char [6].

but another coal char [10] is higher. Its BET value with $\mathrm{N}_{2}$ was $105 \mathrm{~m}^{2} \mathrm{~g}^{-1}$, but was $485 \mathrm{~m}^{2}$ $\mathrm{g}^{-1}$ with $\mathrm{CO}_{2}$. The latter figure would reduce the line to near Eq. 1. A petcoke tested by Johnsson [8] at 30 to 1,000 ppm NO was found to have half order kinetics, but gives similar values to Eq. 1 at those concentrations. However, when extrapolated to 1 atm partial pressure, it falls well below the line of Eq. 1 in Fig. 2.

One interesting aspect to emerge from Aarna and Suuberg's review is that when graphites and non-coal chars are compared, the graphites cluster toward the lower end of the reactivity scale on a mass basis. However, on an area basis they stand out as more reactive and it is concluded that these carbons must have a higher ratio of reactive to non-reactive carbons than other more disordered carbons. They note the work of Chu and Schmidt [9] that suggests basal plane attack at low temperatures. In this regard, $\mathrm{Li}$ [10] has investigated differences in reactivity between chars prepared by different techniques from two coals. He measured the extent of active sites, and found that the reactive surface areas (RSA) were proportional to the total (BET) surface areas. Thus, the RSA concept was no better than BET area in identifying differences in reactivity. In his study the catalytic effect of coal minerals was slight, and only added $\mathrm{Ca}, \mathrm{K}$, and $\mathrm{Na}$ gave significant increases.

The scatter of data in Fig. 2 suggests that BET area is an inadequate basis for the expression of reactivity, a conclusion expressed as early as 1983 by Radovic et al. [11]. In the same context, Aarna and Suuberg [12] showed that micropores hardly participate in the reaction between oxygen and carbon. Because most of the surface area reported in BET measurements is associated with micropores, its use in expressing reactivity is open to question.

Some data for the NO reaction with a carbon whose surface area for reaction is known would help to resolve the issue. Such data are available in the form of carbon black, reacted at temperatures of 1,500 to $2,000 \mathrm{~K}$ in a shock tube [13]. The carbon black was a commercial product consisting of aggregates of carbon spherules 30 $\mathrm{nm}$ in diameter, with a surface area measured by BET of $254 \mathrm{~m}^{2} \mathrm{~g}^{-1}$. This surface is mostly external and therefore accessible to the reactant gas, viz. $1 \%$ vol. NO in a mixture of nitrogen and argon. These results [13] calculated for 955 ppm of NO are plotted in Fig. 2. The activation energy is low, and the data set is 50 to 60 times greater than the general correlation [1] of Eq. 1. Our petroleum coke results also fall near this region. A possible expression for the kinetics of the $\mathrm{C}-\mathrm{NO}$ reaction is therefore a relation similar to Eq. 1, but with the pre-exponential factor increased by a factor of, say 60 . Then

$$
\begin{aligned}
\mathrm{k}_{\mathrm{NO}}= & 3.05 \times 10^{3} \exp (-15939 / \mathrm{T}) \\
& \mathrm{mol}_{\mathrm{NO}} \mathrm{m}^{-2} \mathrm{~s}^{-1} \mathrm{~atm}_{\mathrm{NO}}^{-1}
\end{aligned}
$$

The question of the appropriate surface area of porous carbons for use with Eq. 10 must be resolved. Aarna and Suuberg [12] suggest that the largest changes in pore size occur in pores greater than $10 \mathrm{~nm}$ in size, for both oxygen and $\mathrm{NO}$ as reactant. For a pore of radius or slit width $b(\mathrm{~m})$, the specific surface area is given by

$\mathrm{S}_{\mathrm{p}}=\frac{2 \mathrm{v}_{\mathrm{p}}}{\mathrm{b}} \quad \mathrm{m}^{2} \mathrm{~kg}^{-1}$

where $v_{p}$ is the specific volume of the pore $\left(\mathrm{m}^{3}\right.$ $\left.\mathrm{kg}^{-1}\right)$. 
The distribution of pore sizes in $\mathrm{mm}$ size lumps of petroleum coke before and during combustion at temperatures between 700 to $900^{\circ} \mathrm{C}$ as measured by mercury porosimetry has been reported by Jung [14]. The fine pores in carbon are probably of slit shape, but the output from a porosimeter assumes cylindrical pores. However, because the porosimeter measurement relies on surface tension, which acts along the line of contact, the pore size reported can be considered as either slit width or pore radius. Jung's data indicate that almost all the removal of carbon is associated with pores of size greater than $100 \mathrm{~nm}$, even at the lowest temperatures when complete penetration of oxygen is expected. Tyler [15] found the same effect with petcoke at the extremely low temperature of $450^{\circ} \mathrm{C}$. The mercury pressure during the porosimeter tests on our samples was taken to 62 $\mathrm{Mpa}$, equivalent to pores sizes of $10 \mathrm{~nm}$. The contribution to the surface area from pores smaller than and $10 \mathrm{~nm}$ would be significant, but compressibility and crushing effects become important and the measurement becomes unreliable. The measurements were corrected for interparticle voidage and compressibility [16]. The areas deduced from the porosimetry of the four samples are listed in Table 1 as $\mathrm{Hg}_{20}$, using $20 \mathrm{~nm}$ as the arbitrary cutoff point. They indicate that the $\mathrm{Hg}_{20}$ of the two petroleum cokes are approximately the same as the BET areas, but are much smaller for the activated carbon and chars.

The experimental results are replotted in Fig. 3 with the surface area calculated as $\mathrm{Hg}_{20}$. It should be noted that the results for $\mathrm{Hg}_{10}$ are similar and there is almost an equivalent amount of scatter, as the plots in Fig. 1 show the same trends. The effective diffusion co-efficients were recalculated for $\mathrm{Hg}_{20}$ and the new effectiveness factors are listed in Table 2. The values are greater than found with BET areas and approach unity. In Fig. 3 the petroleum cokes again fall near the line of Eq. 10 because of the correspondence between $\mathrm{Hg}_{20}$ and BET areas. The carbon black data in Fig. 1 are also recalculated to the external surface area. It has been shown that during combustion of carbon black with oxygen at these temperatures, only the external surface of the spherules participates [17]. From the spherule diameter, this can

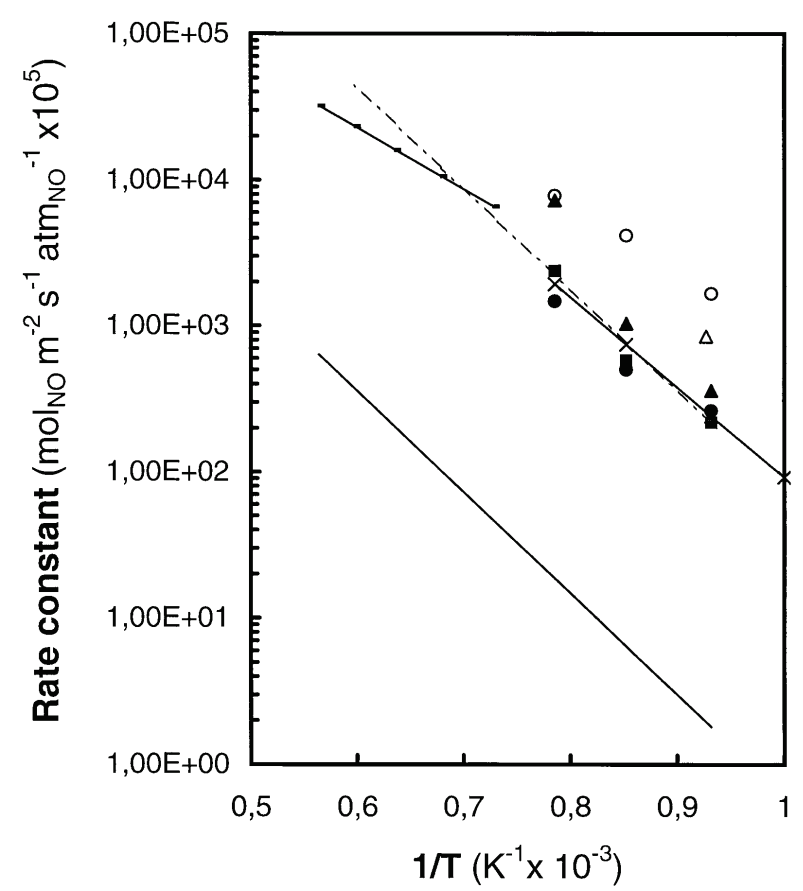

Fig. 3. Dependence of the $\mathrm{C}-\mathrm{NO}$ reaction rate on temperature, specified on $\mathrm{Hg}_{20}$ areas. Symbols as for Fig. 1, except - - - - - is Eq. 12.

be calculated as $120 \mathrm{~m}^{2} \mathrm{~g}^{-1}$, which is typical for carbon blacks. The generalized line of fit in Fig. 3 is therefore changed to 120 times Eq. 1, that is, $2 \times$ Eq. 10:

$$
\begin{aligned}
& \mathrm{k}_{\mathrm{NO}}= 6.1 \times 10^{3} \exp (-15940 / \mathrm{T}) \\
& \mathrm{mol}_{\mathrm{NO}} \mathrm{m}^{-2} \mathrm{~s}^{-1} \mathrm{~atm}_{\mathrm{NO}}^{-1}
\end{aligned}
$$

where area is expressed as $\mathrm{Hg}_{20}$.

The Ivan char data falls somewhat above Eq. 12 , which may be the result of catalytic effects. This material contains more mineral matter than the other materials. In addition, the char value of Johnsson [6] which agreed with Eq. 1 on a BET basis $\left(150 \mathrm{~m}^{2} \mathrm{~g}^{-1}\right)$ now fits Eq. 12 when the area is $\mathrm{Hg}_{20}$ (reported as $1.3 \mathrm{~m}^{2} \mathrm{~g}^{-1}$ ). As the ratio of $\mathrm{BET} / \mathrm{Hg}_{20}$ areas tends to lie around 50 for many coal chars, they fit both approaches. The coal char data of $\mathrm{Li}$ [10] now lie near Eq. 12 with a $\mathrm{Hg}_{20}$ value of $10 \mathrm{~m}^{2} \mathrm{~g}^{-1}$ estimated from the sum of areas of the macropores (volume $0.106 \mathrm{~cm}^{3} \mathrm{~g}^{-1} @ 45 \mathrm{~nm}$ ) and mesopores $\left(0.046 \mathrm{~cm} \mathrm{[3]} \mathrm{g}^{-1} @ 20 \mathrm{~nm}\right)$. The better grouping of the data in Fig. 3 compared to Fig. 2 indicates that for our samples the porosimeter area $\mathrm{Hg}_{20}$ is a better basis for expressing reactivity. It has not been shown here that pores below the $20 \mathrm{~nm}$ size limit do not 
participate in the reaction, but rather that this assumption improves the correlation of reactivity for our and some other data. As a side benefit, it also simplifies the difficult task of estimating effectiveness factors for all but very porous chars at high temperatures. It should be borne in mind that there will always be uncertainty about porosimetry measurements, because of the effects of pore shape, surface wetting, pore connectivity, and so forth.

Smith [18] collected an extensive data set for the oxidation of carbons by oxygen and comments that petroleum coke is more reactive than other carbons. From his plot the difference is a factor of $\sim 50$, similar to that here with NO. If one speculates about the reason for the apparent inactivity of the surface area in the fine pores, it may be because this surface is almost exclusively basal plane material between the laminae of the graphitic sheets [19]. However, reconciliation must be made with conflicting results, for example other petroleum cokes. Assuming that BET and $\mathrm{Hg}_{20}$ areas are similar, the careful measurements of Johnsson [8] do not fit this analysis. For other literature data, there is not enough information to check the result. The choice of Chan's correlation [3] for the kinetics of the $\mathrm{C}-\mathrm{NO}$ reaction in CFD modeling [2] appears to be justified, and may in fact give lower values than required.

\section{CONCLUSION}

The apparent reactivities for the $\mathrm{C}-\mathrm{NO}$ reaction of four pyrolyzed carbons was obtained in the temperature range 800 to $1,000^{\circ} \mathrm{C}$, that is, above the 'break' point in Arrhenius plots. Better correlation was obtained when the rates were calculated with the surface area associated with macropores and some mesopores $(>20 \mathrm{~nm}$ by mercury porosimetry) than with BET areas. The recommended correlation for the rate constant is

$$
\begin{aligned}
& \mathrm{k}_{\mathrm{NO}}= 6.1 \times 10^{3} \exp (-15940 / \mathrm{T}) \\
& \mathrm{mol}_{\mathrm{NO}} \mathrm{m}^{-2} \mathrm{~s}^{-1} \mathrm{~atm}_{\mathrm{NO}}^{-1}
\end{aligned}
$$

The authors acknowledge the support of Lafarge Ciments in providing the samples and funding this work.

\section{REFERENCES}

1. Aarna, I., and Suuberg, E. M., Fuel 76:475 (1997).

2. Visona, S., and Stanmore, B. R., Combust. Flame 106:207 (1996).

3. Chan, L. K., Sarofim, A. F., and Beer, J. M., Combust. Flame 52:37 (1983).

4. Van de Steene, L., Salvador, S., and Charnay, G., Combust. Sci. Technol. 159:255 (2000).

5. Satterfield, C. N., Mass Transfer in Heterogeneous Catalysis, MIT Press, 1970.

6. Johnsson, J. E., and Jensen, A., Twenty-eighth Symposium (International) on Combustion, The Combustion Institute, Edinburgh, 2000, p. 2353.

7. Johnnson, J. E., Fuel 73:1398 (1994).

8. Johnsson, J. E., CHEC Report 9003 Danish Technical University, March 1990.

9. Chu, X., and Schmidt, L. D., IEC Research 32:1359 (1993).

10. Li, H., PhD Thesis, University of Queensland (1999).

11. Radovic, L. R., Walker, Jr, P. L., and Jemkins, R. G., Fuel 62:849 (1983).

12. Aarna, I., and Suuberg, E. M., Twenty-seventh Symposium (International) on Combustion The Combustion Institute, Philadelphia, 1998, p. 2933.

13. Cheng, M. T., Kirsch, M. J., and Lester, T. W., Combust. Flame 77:213 (1989).

14. Jung, K., Fuel 66:774 (1984).

15. Tyler, R. J., Fuel 65:213 (1986).

16. Stanmore, B. R., He, Y., White, E. T., Firth, B., O'Brien, G., and O'Brien, M., Fuel 76:215 (1997).

17. Gilot, P., Bonnefoy, F., Marcucilli, F., and Prado G., Combust. Flame 95:87 (1993).

18. Smith, I. W., Fuel 57:409 (1978).

19. McEnany, B., and Mays, T. J., In H. Marsh, Ed., Introduction to Carbon Science, Butterworths, London, 1989. 